\title{
Nicotinamide decreases MHC class II but not MHC class I expression and increases intercellular adhesion molecule-1 structures in non-obese diabetic mouse pancreas
}

\author{
G Papaccio ${ }^{1}$, E Ammendola ${ }^{1}$ and F A Pisanti ${ }^{2,3}$ \\ ${ }^{1}$ Institute of Histology, Second University of Naples, Naples, Italy \\ ${ }^{2}$ Department of Clinical Pathology, ASL NA4, 80044 Ottaviano, Naples, Italy \\ ${ }^{3}$ Department of Cell Biology, University of Calabria, Cosenza, Italy \\ (Requests for offprints should be addressed to G Papaccio, 21 via Giuseppe Bonito, 80129 Napoli, Italy)
}

\begin{abstract}
Pancreases of untreated and nicotinamide (NIC)-treated pre-diabetic (10-week-old) and overtly diabetic (25week-old) female NOD (non-obese diabetic) mice and of NON (non-obese non-diabetic) control mice were studied, with the following results.

(1) Islets and ducts of overtly diabetic untreated NOD mice (25-week-old) were found to express low levels of MHC class I and II molecules, like NON controls, and high levels of adhesive molecules. (2) NIC was able to slightly affect glycaemia and insulitis, slowing down diabetes progression. Moreover it significantly decreased MHC class II expression (but not class I) in vivo by week 10 , and significantly enhanced intercellular adhesion molecule-1 (ICAM-1) expression, mainly by week 25, within the pancreas, where 5-bromo-2'-deoxyuridine positive nuclei and insulin positive cells were present, demonstrating that a stimulation of endocrine cell proliferation occurs. (3) In addition, NIC partly counteracted the fall of superoxide dismutase levels, observed in untreated diabetic NOD animals. (4) In vitro studies demonstrated that NIC: (i) was able to significantly reduce nitrite accumulation and to increase NAD+NADH content significantly, and (ii) was able to increase the levels

of interleukin-4, a T helper 2 lymphocyte (Th2) protective cytokine, and of interferon- $\alpha$ (IFN- $\alpha$ ), which is known to be able to induce MHC class I and ICAM-1 but not MHC class II expression, as well as IFN- $\gamma$, which is also known to be able to induce MHC class I and ICAM-1 expression. The latter, although known to be a proinflammatory Th1 cytokine, has also recently been found to exert an anti-diabetogenic role.

This study therefore clearly shows that adhesive mechanisms are ongoing during the later periods of diabetes in pancreatic ducts of NOD mice, and suggests they may be involved in a persistence of the immune mechanisms of recognition, adhesion and cytolysis and/or endocrine regeneration or differentiation processes, as both NIC-increased ICAM-1 expression and 5-bromo-2'deoxyuridine positivity imply. The effects of NIC on MHC class II (i.e. a reduction) but not class I, and, mainly, on ICAM-1 expression (i.e. an increase), together with the increase in Th2 protective cytokine levels are very interesting, and could help to explain its mechanism of action and the reasons for alternate success or failure in protecting against type 1 diabetes development.

Journal of Endocrinology (1999) 160, 389-400
\end{abstract}

\section{Introduction}

Infiltration by mononuclear cells around and within pancreatic islets is the first morphological evidence of type 1 diabetes. In animal models such as the NOD (non-obese diabetic) mouse, infiltration, especially during the early stages of the disease, is not limited to the islets, but involves the whole pancreas, and its ducts in particular (Papaccio et al. 1993a). Moreover, in addition to the pancreas, infiltration affects other organs such as the thyroid (Asamoto et al. 1984), adrenals (Asamoto et al. 1984), salivary glands (Miyagawa et al. 1986) and Harderian glands (Papaccio et al. 1996).
Immunocytochemical studies in animal models demonstrate that infiltrating cells within and around the islets are Ia-b (class II) immunoreactive cells (Papaccio et al. 1991, 1993b), and that an MHC class II immunoreactivity is expressed on endothelia in diabetic rats (Bretzel et al. 1990). Nicotinamide (NIC), an inhibitor of poly ADP ribose synthetase, thought to be protective for islet $\beta$ cells in NOD mice (Yamada et al. 1982), has been shown to inhibit class II but not class I expression in mouse islet cells in culture (Yamada et al. 1990).

Several adhesion molecules participate in various immune responses and have been shown to be involved in the pathogenesis of autoimmune diseases. Intercellular 
adhesion molecule-1 (ICAM-1) is a well-characterized surface glycoprotein belonging to the immunoglobulin superfamily. The ICAM-1 molecule has been shown to be involved in various leukocyte functions, including T-cell differentiation, antigen presentation and extravasation into lymphoid and inflamed non-lymphoid tissues (Dustin et al. 1986, 1988, Springer 1990). In addition, expression of ICAM-1 can be induced on a variety of cells at the site of inflammation by cytokines; ICAM-1 is also involved in recognition, adhesion and cytolysis by killer lymphocytes (Dustin et al. 1986, Makgoba et al. 1988). An increased expression of adhesion molecules has been described in the diabetic human pancreas, mainly on endothelial cells (Hänninen et al. 1992). In the NOD mouse, MHC class II and ICAM-1 immunoreactivities have been observed in pancreatic endothelial cells (Linn et al. 1994) and around pancreatic ducts in pre-diabetic animals (Papaccio et al. 1995).

Expression of ICAM-1 has recently been observed on NOD pancreatic islet $\beta$ cells (Yagi et al. 1995). This phenomenon, induced by inflammatory cytokines, seems to facilitate the destruction of islet $\beta$ cells by CD8 cytotoxic lymphocytes (CTL). While ICAM-1 expression on vascular endothelium and on pancreatic islet $\beta$ cells has been partly explained, its significance at the level of pancreatic ducts seems to be rather more complex. Tissue non-specific cellular adhesion molecules (CAMs) have been interpreted as co-stimulatory molecules in the 'local' immune response (Yang et al. 1996). It has also been shown that both interferon- $\alpha$ (IFN- $\alpha$ ) and IFN- $\gamma$ are able to induce MHC class I and ICAM-1, but not MHC class II, expression (Chakrabarti et al. 1996). On the other hand, anti-ICAM-1 treatment has been shown to induce tolerance (Isobe et al. 1992), and ICAM-1 expression in inflamed islets during disease progression up to 17 weeks of age does not appear to be modified (Yang et al. 1996). Therefore, ICAM-1 expression and its interactions with leucocyte-function-associated antigen-1 (LFA-1) seem to be not only as important as other CAM (namely L-selectins) pathways in the control of tissue-selective lymphocyte homing, but also in other poorly known phenomena such as specific cell-cell interactions in embryogenesis and histogenesis.

NIC has been shown to stimulate cell replication (Sandler \& Andersson 1988), to form islet-like cell clusters (Sandler et al. 1989) and to be a potent inducer of endocrine differentiation in cultured human fetal pancreatic cells (Otontoski et al. 1993). In the majority of these instances pancreatic ducts are involved in regeneration, and their role in this process in the adult pancreas has been reconsidered recently (Bonner-Weir et al. 1993, Wang et al. 1995). Like NIC, superoxide dismutase (SOD)-polyethylene glycol has been shown to moderately suppress the induction of class II molecules (Yamada et al. 1993). This shows indirectly that hydroxyl radicals may also play a role in class II antigen expression.
In view of these findings, our aim was to investigate islet and pancreatic duct MHC class I, II and ICAM-1 molecule expression, as well as the cytokine profile, both in untreated and NIC-treated pre-diabetic and overtly diabetic NOD mice, in order to define better their significance, relevance, time of appearance and role.

\section{Materials and Methods}

\section{Animals}

Five-week-old $(n=30)$ female NOD mice (purchased from Bommice, Bomholtgarten, Denmark) were used for the experiment. In this colony, clinically evident diabetes is observable by week 22 in $90-100 \%$ of females but in less than $20 \%$ of males. The first histopathological lesion is peri-vasculitis, seen by week 5 . Peri-insulitis and periductulitis are present by weeks $8-10$; by week 15 insulitis is massive.

\section{In vivo experiments}

Animals, free from viral or bacterial infections, and weighing $20-35 \mathrm{~g}$, were not subjected to insulin treatment. Twenty mice were treated with a $10 \%$ aqueous solution of NIC (Sigma, Milan, Italy) at a dose of $0.5 \mathrm{mg} / \mathrm{g}$ body weight/day i.p. from week 5 (non-diabetic insulitisfree period) to week 20 (pre-clinical diabetic period). The remaining animals $(n=10)$ were untreated (NOD untreated controls).

Animals were anaesthetized with ether and the pancreases removed for morphological evaluation at week 10 or 25 . These time-points were chosen because at week 10 insulitis is already present and at week 25 animals are overtly diabetic. The NON (non-obese non-diabetic) mouse is another albino strain obtained by Dr M Hattori (Joslin Diabetes Center, Boston, MA, USA), which is a diabetes-resistant control strain containing a diabetesresistant gene. Twenty females of this strain and of the same age were used as non-diabetic controls. Half of them $(n=10)$ were treated with NIC, as described above, and the remainder were untreated. For islet cell culture, untreated 10-week-old NOD and NON animals $(n=15$ per group) were used (see below). For in vivo labelling of proliferating cells, NOD and NON animals, both NIC-treated and untreated ( $n=5$ per group), were used (see below).

\section{Glycaemia}

Blood glucose levels were tested weekly using the hexokinase method (Boehringer, Mannheim, Germany). Animals were considered hyperglycaemic when their non-fasting blood glucose levels were higher than 
$8 \mathrm{mmol} / \mathrm{l}$ but lower than $12 \mathrm{mmol} / \mathrm{l}$ at two successive determinations. Mice were considered diabetic when their blood glucose levels exceeded $12 \mathrm{mmol} / \mathrm{l}$.

\section{Standard light microscopy}

Pancreatic samples from each animal were fixed with Bouin's fixative and embedded in paraffin. Specimens were sectioned serially ( $5 \mu \mathrm{m}$ thick) and stained with haematoxylin-eosin or Gomori aldehyde fuchsin for general morphology, and for the evaluation of islet and extra-islet infiltration.

\section{Immunocytochemistry}

Samples from the tail of each pancreas were collected and kept frozen in liquid nitrogen. Randomly selected cryocut sections were stained by the avidin-biotin peroxidase indirect staining method as previously described (Papaccio et al. 1991). At least 30 ducts and islets per pancreas were observed.

The monoclonal antibodies used in this experiment were: anti-MHC class I (HLA-ABC; Dakopatts, Milan, Italy), anti-MHC class II (Ia-b HLA-DR $\beta$ chain, IgG $_{1}$; Dakopatts), anti-ICAM-1 rat anti-mouse (CD45, clone 84H10; Dakopatts), anti-T lymphocyte antibodies (Dakopatts), including CD4 (MT310) and CD8 (DK24), anti-macrophage antibody $\mathrm{BM} 8$, which detects murine pan macrophages (BMA Biomedicals AG, Augst, Switzerland), anti-insulin, anti-glucagon and antisomatostatin antibodies (Dakopatts). Secondary antibody was biotinylated goat anti-rat (Dakopatts). As the negative control, the primary antibody was substituted with rat non-immune serum.

Sections $5 \mu \mathrm{m}$ thick were observed for semiquantitative analysis. The immunoreactive elements on alternate sections were determined at a magnification of $\times 400$ using an eyepiece with a square-ruled grid with a total area of $0.062 \mathrm{~mm}^{2}$ and counted with an M4 image analysis system (Imaging, Brock University, St Catherines, Ontario, Canada) in 60 different areas. This allowed the calculation of immunoreactive cells per $\mathrm{mm}^{2} \pm$ S.E.M.

\section{In vivo labelling for proliferating cells}

In vivo pulse labelling with 5-bromo-2'-deoxyuridine (BrdU) (Sigma), a thymidine analogue, and immunostaining of the incorporated BrdU were used to mark the cells that had synthesized DNA during the incubation period. Ten hours before killing, BrdU (100 mg/kg body weight, freshly dissolved in PBS) was injected i.p. into 25-weekold untreated $(n=5)$ and NIC-treated (week 5 and week 20) $(n=5)$ NOD mice and NON controls ( $n=5$ per group). The number of immunostained nuclei was quantified. At least ten ducts per pancreas were viewed. Detection of granule-containing endocrine cells was accomplished with anti-insulin antibody. For double labelling to BrdU and insulin, deparaffinized sections were washed first in hydrochloric acid $(0.5 \mathrm{~mol} / 1,10 \mathrm{~min})$, followed by incubation with primary anti-BrdU antibody (Dakopatts). Sections were then incubated overnight $\left(4^{\circ} \mathrm{C}\right)$ with the second primary antibody to insulin.

\section{SOD assay}

Total SOD activity, as well as $\mathrm{Cu}-\mathrm{Zn}$ SOD and Mn SOD in extracts, was measured by the xanthine/xanthine oxidase, cytochrome C reduction method (McCord \& Fridovich 1969) and values were expressed as U/mg protein.

\section{Islet cell culture}

Pancreatic islets were isolated by digestion with collagenase type IV (Sigma) from untreated 10-week-old NOD and NON ( $n=15$ per group) mice (Brunstedt et al. 1984). After isolation, islets were pre-cultured for 3-7 days in RPMI 1640 (Sigma) supplemented with 10\% fetal calf serum at $37^{\circ} \mathrm{C}$ in humidified atmospheric air. Then, 150 islets $/ 300 \mu \mathrm{l}$ medium were incubated for $24 \mathrm{~h}$ in RPMI 1640 supplemented with $0 \cdot 2 \% \mathrm{BSA}$, with or without 10 or $20 \mathrm{mmol} / 1 \mathrm{NIC}$, and the culture was continued for 6 days, with the medium being changed after 3 days.

\section{$N A D+N A D H$ and nitrite accumulations}

The media were taken for assessment of accumulated nitrite concentrations (see below). Groups of 50-100 islets were incubated for $60 \mathrm{~min}$ in plastic tubes containing $100 \mu \mathrm{l}$ Krebs-Ringer bicarbonate buffer, and then retrieved for NAD+NADH determination (Strandell et al. 1988).

For the nitrite assay, culture media samples $(150 \mu \mathrm{l})$ were mixed with an equal volume of the Griess reagent (1 part $0 \cdot 1 \%$ naphthylethylene diamine dihydrochloride and 1 part $1 \%$ sulphanilamide in $\left.5 \% \mathrm{H}_{3} \mathrm{PO}_{4}\right)$ and incubated for $10 \mathrm{~min}$ at room temperature (Green et al. 1982). The absorbance at $550 \mathrm{~nm}$ was measured and the concentration of nitrite was determined by means of a sodium nitrite standard curve. The detection limit was $1 \mu \mathrm{mol} / \mathrm{l}$, corresponding with $2 \mathrm{pmol} /$ islet in our experiment.

\section{Cytokine profile}

Groups of islets (500 per dish), cultured as above described, were harvested by pipetting, centrifuged to a pellet $(200 \mathrm{~g}$, $2 \mathrm{~min}$ ), the supernatant removed, and used for measurement of interleukin-2 (IL-2), IL-4, IFN- $\gamma$, IFN- $\alpha$ or tumour necrosis factor- $\alpha$ (TNF- $\alpha$ ) levels following centrifugation for $5 \mathrm{~min}$ at 2000 r.p.m. to eliminate cell debris. The concentrations of IL-2, IL-4, IFN- $\gamma$, IFN- $\alpha$ and TNF- $\alpha$ were measured by ELISA using monoclonal 


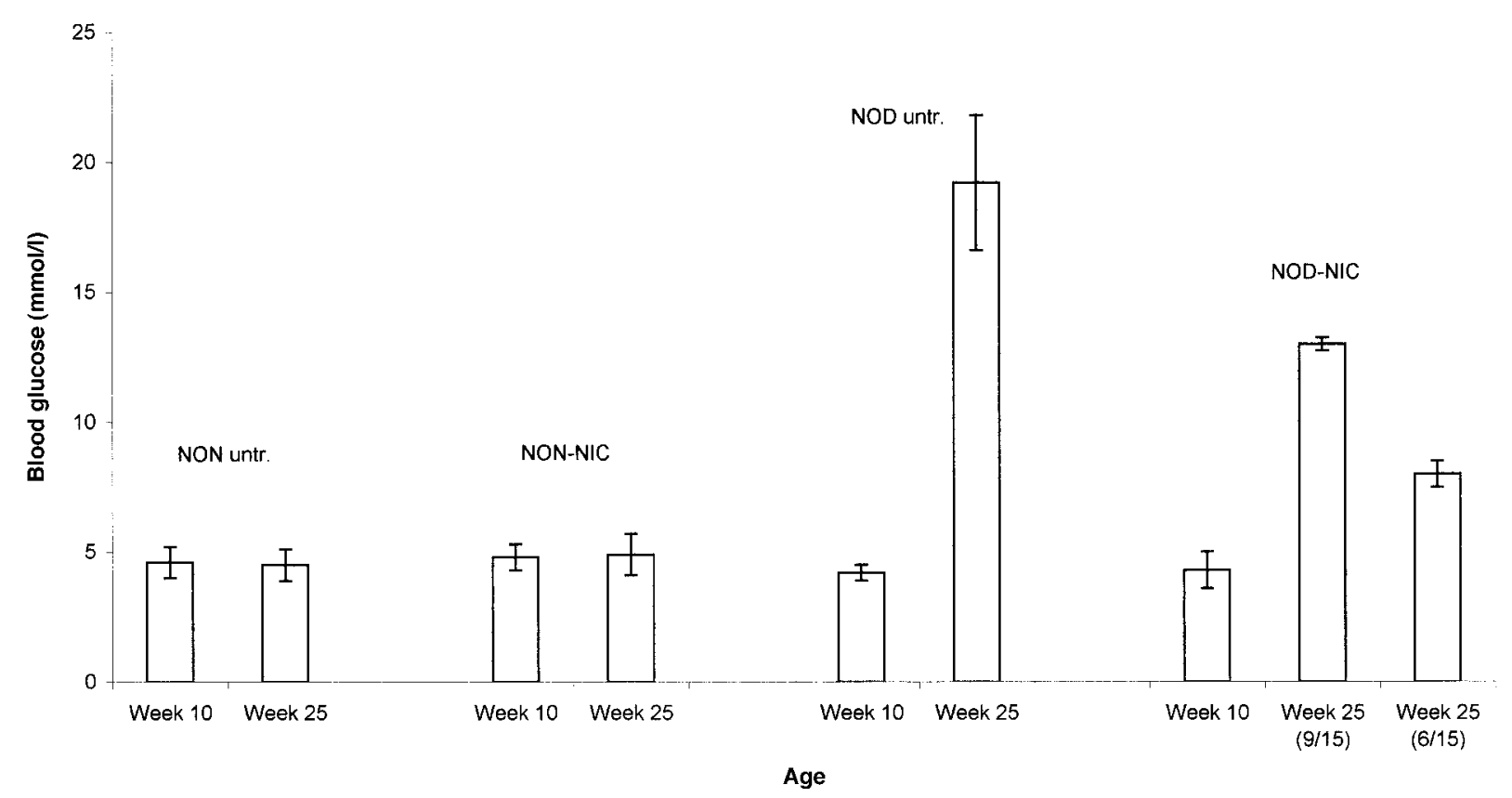

Figure 1 Blood glucose levels (values are expressed as mmol/I \pm S.D.) in NOD and NON mice, either untreated (untr.) or NIC-treated. The figure shows that NON mice (both untreated and NIC-treated) were normoglycaemic throughout the experiment, and that NOD untreated animals become overtly diabetic by week 25 . NOD-NIC-treated animals, at week 25 , partly become overtly diabetic (9/15) and partly (6/15) showed values still under $12 \mathrm{mmol} / \mathrm{l}$ (hyperglycaemic). The average value for all the fifteen animals of the group was $11 \pm 2 \cdot 5 \mathrm{mmol} / \mathrm{l}$.

antibodies specific for IL-2, IL-4, IFN- $\gamma$, IFN- $\alpha$ and TNF- $\alpha$ (Openshaw et al. 1995). The amount of cytokine present was determined from the standard curves from purified recombinant cytokines. Values are expressed as $\mathrm{U} / \mathrm{ml}$.

\section{Statistical evaluation}

Student's $t$-test was used for statistical analysis and the level of significance was set at $P<0 \cdot 05$. Groups of data were analyzed by ANOVA, followed either by Fisher's test or Student's $t$-test. When Student's paired $t$-test was used, $P$ values were corrected for multiple comparisons using the Bonferroni method (Wallenstein et al. 1980). Data are given as means \pm S.D.

\section{Results}

NIC affects glycaemia slowing down diabetes progression

Blood glucose levels are shown in Fig. 1. The mean \pm S.D. non-fasting blood glucose level at week 10 was found to be $4 \cdot 2 \pm 0.3 \mathrm{mmol} / 1$ for untreated NOD, $4 \cdot 3 \pm 0.7$ for NIC-treated NOD, $4 \cdot 6 \pm 0 \cdot 6$ for untreated NON controls and $4.5 \pm 0.6$ for NIC-treated NON controls. These animals, therefore, were considered to be normoglycaemic. The mean value for 25 -week-old untreated NOD mice was $19 \cdot 2 \pm 2.6 \mathrm{mmol} / 1 \quad(P<0.0001$ vs week 10$)$, with $11 \cdot 0 \pm 2.5$ for NIC-treated NOD animals $(P<0 \cdot 001$ vs week 10). In the latter group (NIC-treated NOD animals), 9/15 mice showed values exceeding $12 \mathrm{mmol} / 1$ and the remaining $6 / 15$ animals showed values which were still less than $12 \mathrm{mmol} / \mathrm{l}$. Therefore, the untreated NOD animals were considered to be overtly diabetic, along with 9/15 NIC-treated NOD mice, while the remaining 6/15 NIC-treated NOD animals were considered to be hyperglycaemic but not overtly diabetic.

Control NON mice (both untreated and NIC-treated) at week 25 were always normoglycaemic (with values of $4 \cdot 8 \pm 0.5$ and $4.9 \pm 0 \cdot 8 \mathrm{mmol} / 1$ respectively).

NIC partly affects insulitis progression

Control NON (untreated and NIC-treated) mice always had normal islets and ducts, and no signs of infiltration were observed.

Untreated 10-week-old NOD mice showed clear signs of infiltration by mononuclear cells. Infiltrating cells (mainly monocytes/macrophages) were observed within small post-capillary vessels or in perivascular areas surrounding non-islet ducts, within the connective tissue of these ducts and within the epithelial layer.

Diabetic 25-week-old untreated NOD mice only occasionally showed signs of insulitis. Islets were mostly 
Table 1 Quantitative evaluation of pancreatic duct positive cells in untreated and NIC-treated NOD and NON control mice. Data are given as positive cells $/ \mathrm{mm}^{2} \pm$ S.E.M. The table shows that 25-week-old NOD-NIC-treated animals still expressed high amounts of ICAM-1 structures but that they did not express significant amounts of MHC class I and II molecules. NIC treatment significantly decreased MHC class II (but not class I) expression and significantly enhanced ICAM-1 expression both in NOD and NON animals

\section{Week 10}

\begin{tabular}{|c|c|c|c|c|c|}
\hline & & Week 10 & & Week 25 & \\
\hline & Strain & Untreated & NIC-treated & Untreated & NIC-treated \\
\hline Antibody & & & & & \\
\hline MHC class I & NOD & $14 \pm 3$ & $15 \pm 4$ & $1 \pm 0 \cdot 2$ & $2 \pm 1$ \\
\hline & $\mathrm{NON}$ & $1 \pm 0 \cdot 2$ & $3 \pm 0 \cdot 6$ & $1 \pm 0 \cdot 2$ & $2 \pm 0 \cdot 6$ \\
\hline MHC class II & NOD & $17 \pm 1 \cdot 0^{a, b}$ & $7 \pm 2^{\mathrm{a}}$ & $3 \pm 0 \cdot 5$ & $1 \pm 0 \cdot 5$ \\
\hline & $\mathrm{NON}$ & $1 \pm 0 \cdot 2$ & $1 \pm 0 \cdot 1$ & $1 \pm 0 \cdot 5$ & $1 \pm 0 \cdot 2$ \\
\hline ICAM-I & NOD & $10 \pm 0.5$ & $13 \pm 2^{\mathrm{c}}$ & $3 \pm 0 \cdot 5$ & $13 \pm 3^{d}$ \\
\hline & $\mathrm{NON}$ & - & $4 \pm 1$ & - & $4 \pm 1$ \\
\hline BM8 & NOD & $3 \pm 0 \cdot 1$ & $3 \pm 0 \cdot 1$ & - & - \\
\hline & NON & - & - & - & - \\
\hline CD4 & NOD & - & - & $2 \pm 0 \cdot 2$ & $3 \pm 0 \cdot 5$ \\
\hline & $\mathrm{NON}$ & - & - & - & - \\
\hline CD8 & NOD & $2 \pm 0 \cdot 1$ & $3 \pm 0 \cdot 1$ & $1 \pm 0 \cdot 1$ & $4 \pm 0 \cdot 2$ \\
\hline & $\mathrm{NON}$ & - & - & - & - \\
\hline
\end{tabular}

${ }^{\mathrm{a} P}<0.001$ vs 25 -week-old NOD mice and vs NON controls; ${ }^{\mathrm{b}} P<0.001$ vs week 10 NIC-treated animals; ${ }^{c} P<0 \cdot 01$ vs MHC class II week 10 NIC-treated animals; ${ }^{d} P<0 \cdot 0001$ vs week 25 untreated animals

(Student's t-test).
Week 25 small (atrophic or retracted with evident signs of cytoarchitectural derangement). The ducts were also devoid of infiltration and showed no signs of destruction.

NIC treatment in NOD mice slightly affected the progression of insulitis, which showed a less severe progression of inflammation. The findings observed at week 10 were quite similar to those observed in untreated NOD pancreas. Several islets were still infiltrated (showing an intra-islet infiltration) at week 25 , when the islets and ducts were also surrounded by mononuclear cells in 6/15 animals (the same animals showed less severe hyperglycaemia). Evident signs of islet atrophy and of cytoarchitectural derangement were observed in 9/15 animals which were also overtly diabetic.

\section{NIC decreases MHC class II, but not class I, and increases ICAM-1 expression}

Semi-quantitative evaluations are summarized in Table 1.

Untreated 10-week-old NOD mice showed both MHC class I and class II (Ia-b) molecules within the whole pancreas. Positivity for MHC class I and II structures was significantly higher with respect to that for ICAM-1 structures $(P<0 \cdot 001)$. Positivity for MHC class I and, mainly, for class II molecules (Fig. 2a) was observed within the connective tissue surrounding the ducts (mainly infiltrating cells), and was different from that reported in our previous work in 8-week-old NOD mice (Papaccio et al. 1995) at the level of the epithelial layer of the ducts. Often the whole epithelial layer was positive for Ia-b (Fig. 2a) as well as ICAM-1 molecules (Fig. 2b). For islet ducts this positivity extended to the islets. ICAM-1 structures were often observed in groups on cells of the connective layer surrounding the ducts and on their epithelial cells (Fig. 2b). No differences were observed among the animals. ICAM-1 immunoreactive structures also were observed on islet cells and on scattered cells, mainly along septa, within the pancreas (Fig. 2b).

$\mathrm{CD}^{+}$(lymphocyte) and $\mathrm{BM}^{+}$(macrophage) cells were observed only among scattered cells of ducts, either in the connective layer or within the epithelial cell layer (Fig. 2c). $\mathrm{BM}^{+}$cells were considerably fewer in number, when compared with the MHC class I, II and ICAM-1 positive cells $(P<0 \cdot 001)$. In particular, one could observe that while MHC class I and II (Ia-b) and ICAM-1 structures clearly were expressed by epithelial cells of the ducts, BM8 or CD8 structures were expressed only by infiltrating cells located either in the connective layer or in between epithelial cells. Occasionally, isolated insulin positive cells were seen along ducts.

Positivity for insulin, glucagon and somatostatin was normal within islets, where a CD8 positivity was also present.

In 25-week-old untreated diabetic NOD animals, MHC class I and II molecules were only rarely observed on islets and pancreatic ducts, but ICAM-1 expression (Fig. 2d) was, unexpectedly, still observable; these structures were decreased when compared with those observed in 10-week-old animals but were more abundant than MHC class I and II molecules found in animals of the same age $(P<0 \cdot 001)$. Islets only showed rare insulin positive cells but showed a normal pattern for glucagon and 

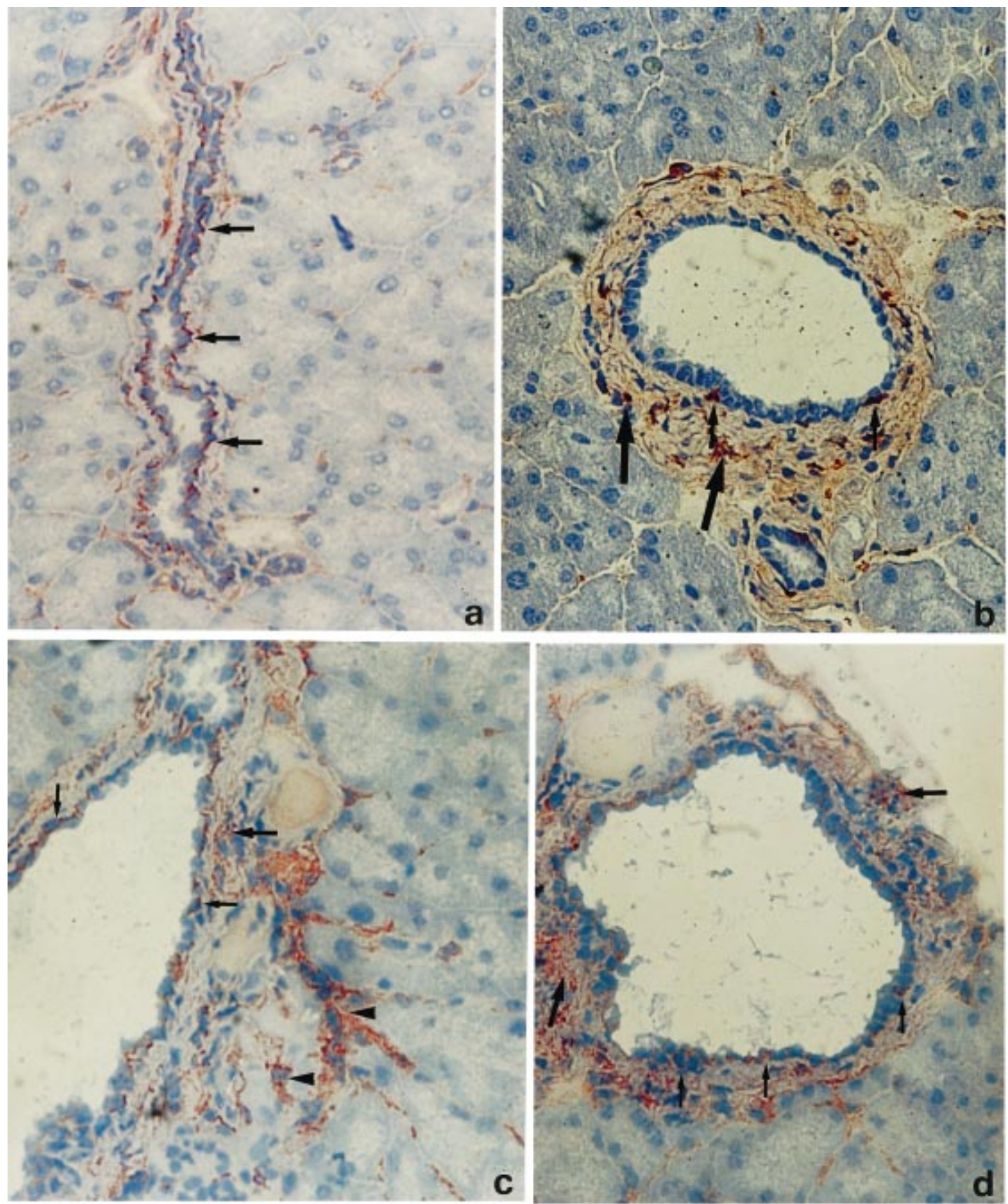

Figure 2 (a) Light micrograph of an untreated 10-week-old NOD mouse pancreas showing la-b ${ }^{+}$epithelial cells of a duct (arrows). The whole epithelial layer expresses la- $b^{+}$molecules on the lateral and basal portions of these cells (original magnification $\times 300$ ). (b) Light micrograph of an untreated 10-week-old NOD mouse pancreas showing $\mathrm{BM}^{+}$ (macrophage) cells (large arrow), scattered within the connective layer, surrounding the duct, and $\mathrm{BM}^{+}$isolated cells within the epithelial layer of the duct (small arrows) (original magnification $\times 300$ ). (c) Light micrograph of an untreated 10-week-old NOD mouse pancreas showing ICAM- $1^{+}$structures located both at the level of the connective layer (large arrows) and at the epithelial layer (small arrows) of a duct. Positivity seems to involve a consistent number of these cells. Several cells along septa (arrowheads) are also ICAM- $1^{+}$(original magnification $\times 300$ ). (d) Light micrograph of an untreated 25-week-old NOD mouse pancreas showing ICAM $-1^{+}$cells of a duct (small arrows). ICAM- $1^{+}$structures are also visible at the level of the connective layer (large arrows) (original magnification $\times 300$ ). 

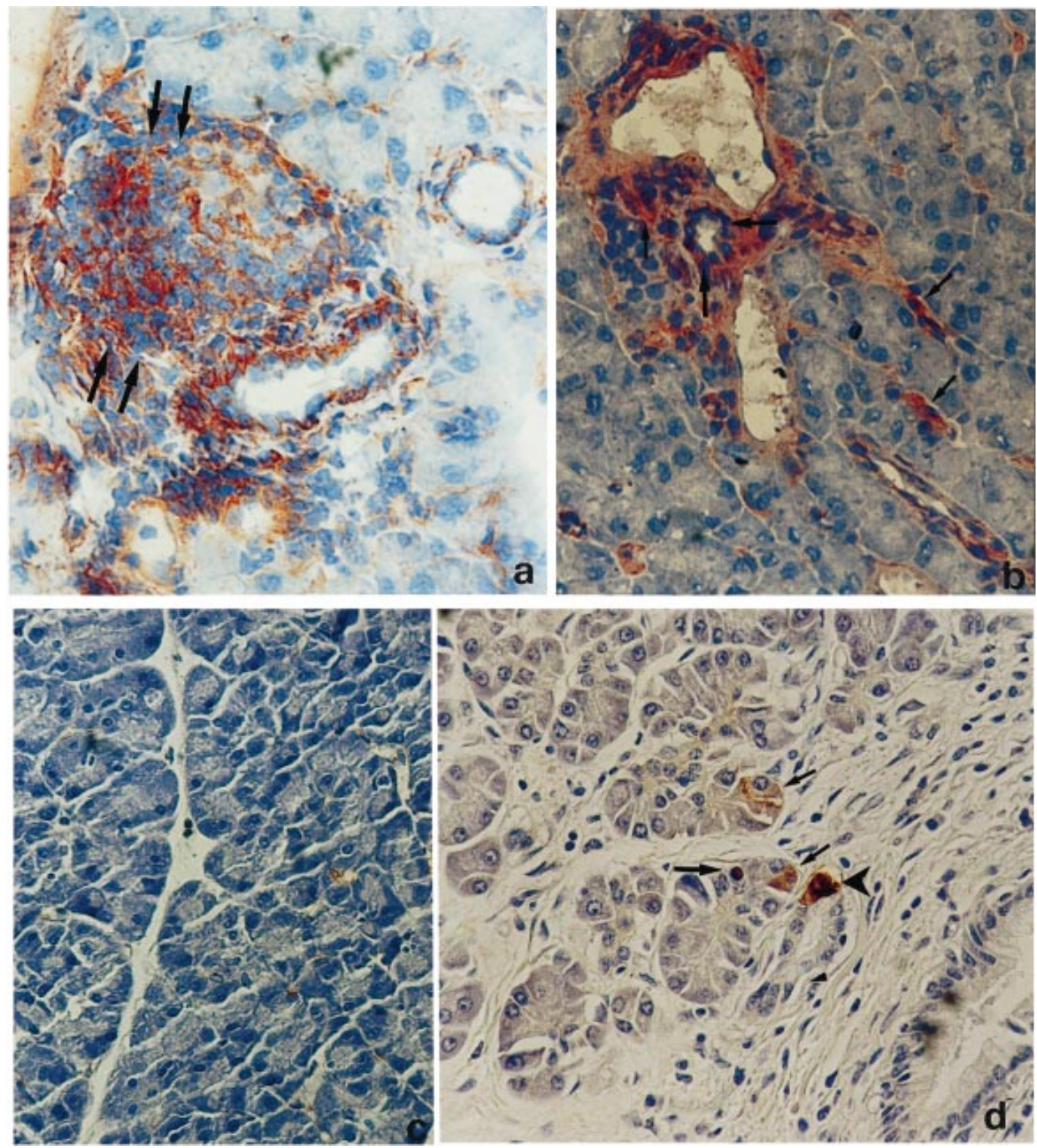

Figure 3 (a) Light micrograph of a 10-week-old NOD animal treated with NIC. ICAM-1 expression involves the infiltrate (arrows) (original magnification $\times 300$ ). (b) Light micrograph of a 25 -week-old NOD animal treated with NIC. ICAM-1 expression is clearly seen at the level of ductal cells (large arrows) as well as within the connective tissue (small arrows) (original magnification $\times 300$ ). (c) Light micrograph of a 25-week-old NON animal untreated with NIC showing no positivity for ICAM-1 molecules (original magnification $\times 300$ ). (d) Light micrograph of a 25-week-old NOD animal treated with NIC. Single-staining for insulin (small arrows) and BrdU (large arrow), and double-stained cells (arrowhead) for the same antibodies are seen (original magnification $\times 300$ ).

somatostatin positive cells. CD8 and BM8 structures were not observed on ducts or in islets, and only a few $\mathrm{CD} 4^{+}$ cells were observed.

NIC-treated 10-week-old NOD females showed a significantly lower expression of Ia-b molecules, but not of MHC class I structures (which were of comparable intensity with respect to untreated controls), and a significant increase in ICAM-1 molecules compared with those found in untreated NOD animals $(P<0 \cdot 001)$. This increased expression, paralleled by a decrease in MHC class II expression (but not that of class I) in 10-week-old animals was observed in the whole pancreas and involved the infiltrate in all the animals (Fig. 3a), although in 25-week-old animals it was 
Table 2 SOD levels in NOD and NON untreated and NIC-treated animals. Data expressed as U/mg protein, are means \pm S.D.

Week 10

\begin{tabular}{|c|c|c|}
\hline T. SOD & Cu-Zn SOD & Mn-SOD \\
\hline $160 \pm 22$ & $125 \pm 15$ & $35 \pm 8$ \\
\hline $175 \pm 35$ & $135 \pm 25$ & $40 \pm 10$ \\
\hline $9 \pm 2 \cdot 0$ & $6 \cdot 5 \pm 1$ & $2 \cdot 5 \pm 1$ \\
\hline $17 \pm 3$ & $13 \pm 2$ & $4 \pm 1$ \\
\hline
\end{tabular}

Week 25

\begin{tabular}{|c|c|c|}
\hline T. SOD & $\mathrm{Cu}-\mathrm{Zn}-\mathrm{SOD}$ & Mn-SOD \\
\hline $169 \pm 29$ & $120 \pm 20$ & $42 \pm 10$ \\
\hline $180 \pm 32$ & $140 \pm 22$ & $40 \pm 10$ \\
\hline $5 \pm 1$ & $3 \cdot 5 \pm 0 \cdot 5$ & $1 \cdot 5 \pm 0.5$ \\
\hline $33 \pm 5$ & $28 \pm 3 \cdot 5$ & $5 \pm 1 \cdot 5$ \\
\hline
\end{tabular}

Untreated NOD mice showed very low levels of total (T.) SOD and of Cu-Zn SOD ( $P<0 \cdot 0001$ vs NON at week 25). NIC-treated animals showed significantly $(P<0 \cdot 001)$ increased values. NIC also raised total SOD values in NON mice $(P<0 \cdot 01$ vs untreated NON). Anova and Students's t-test were used for statistical analysis.

primarily observable on ducts and in small clusters within the pancreas (Fig. $3 b$ ). $\mathrm{BM}^{+}$cells were observed only rarely.

Control untreated NON mice showed a weak MHC class I and II positivity, and were completely negative for ICAM-1, lymphocyte and macrophage antibodies (Fig. 3c). NIC-treated NON animals did show an increased expression of MHC class I and, particularly, of ICAM-1 structures, although only by a small amount when compared with that observed in NIC-treated NOD animals.

\section{NIC stimulates endocrine cell proliferation}

Only NIC-treated NOD animals showed a clear BrdU positivity in some ductal cell nuclei and in nuclei within pancreatic acini (Fig. 3d). Double-staining for insulin confirmed their endocrine nature $(\beta$ cells). The frequency of endocrine insulin-containing $\beta$ cells intercalated in the duct epithelium increased with age in all evaluated animals. The in vivo labelling of cells synthesizing DNA showed a relative expansion of the ductal epithelium, i.e. an attempt at proliferation. BrdU positive nuclei were seen in common pancreatic ducts as well as in focal regions of pancreatic acini (scattered cells). The average number of BrdU positive nuclei counted per pancreas in NIC-treated NOD animals was $280 \pm 30$, and the average number of BrdU and insulin co-stained cells was $95 \pm 15$ per pancreas.

NIC partly counteracts the SOD activity fall observed in diabetic NOD animals

Results are shown in Table 2. Untreated NOD mice showed very low levels of total SOD and, in particular, of $\mathrm{Cu}-\mathrm{Zn} \mathrm{SOD}$, the values of which decreased to extremely low amounts in 25-week-old untreated NOD animals $(P<0 \cdot 0001$ vs NON). NIC counteracted this fall significantly $(P<0 \cdot 001)$ in NOD animals; the increase in values was significant when compared with untreated diabetic animals $(P<0 \cdot 001)$. It was still a very low amount when compared with values found in NON untreated animals $(P<0 \cdot 0001)$. NIC also raised total SOD values in NON mice $(P<0 \cdot 01$ vs untreated $\mathrm{NON})$.
NIC increases $N A D+N A D H$ and decreases medium nitrite contents

Values are shown in Table 3. NAD+NADH content (expressed as pmol/10 islets) was increased significantly after exposure to NIC $(P<0.001$ vs values for untreated controls).

Cultured islets of untreated female NOD mice accumulated significant amounts of nitrite, but NIC added to the medium was able to decrease medium nitrite contents (see Table 2). The lower dose (NIC $10 \mathrm{mmol} / \mathrm{l}$ ) in particular was more effective at decreasing the nitrite content $(P<0 \cdot 0001$ vs untreated NOD), thus suggesting the existence of a dose-dependent response.

NIC increases levels of a Thelper 2 lymphocyte (Th2) protective cytokine IL-4 as well as IFN- $\alpha$ and IFN- $\gamma$

NIC-treated islets from NOD mice showed high levels of IFN- $\alpha(P<0 \cdot 001$ vs NON) as well as IL-4 $(P<0 \cdot 001$ vs NON) production (Fig. 4). In particular, islets treated with higher amounts of NIC $(20 \mathrm{mmol} / \mathrm{l})$ showed the highest levels of IFN- $\alpha \quad(P<0.001$ vs NOD-NIC $10 \mathrm{mmol} / \mathrm{l})$ and IL-4 $(P<0 \cdot 01 \mathrm{vs}$ NOD-NIC $10 \mathrm{mmol} / \mathrm{l})$, as well as of IFN- $\gamma(P<0 \cdot 001$ vs NON and NOD-NIC

Table $3 \mathrm{NAD}+\mathrm{NADH}$ (values are expressed as pmol/10 islets \pm S.D.) and nitrite determinations (values are expressed as pmol/islet/ 6 days \pm S.D.).

\begin{tabular}{|c|c|c|c|}
\hline & Strain & $\mathrm{NAD}+\mathrm{NADH}$ & Medium nitrite \\
\hline \multicolumn{4}{|c|}{ Treatment } \\
\hline \multirow[t]{2}{*}{ None } & $\mathrm{NON}$ & $4 \cdot 5 \pm 1 \cdot 5$ & $12 \pm 4$ \\
\hline & NOD & $4 \cdot 4 \pm 1 \cdot 0$ & $36 \pm 8^{c}$ \\
\hline \multirow[t]{2}{*}{ NIC 10} & $\mathrm{NON}$ & $6 \cdot 8 \pm 1 \cdot 8$ & $6 \pm 2$ \\
\hline & NOD & $6 \cdot 9 \pm 1 \cdot 6$ & $5 \pm 1^{d}$ \\
\hline \multirow[t]{2}{*}{ NIC 20} & $\mathrm{NON}$ & $8 \cdot 6 \pm 1 \cdot 2^{a}$ & $12 \pm 2$ \\
\hline & NOD & $9 \cdot 0 \pm 1 \cdot 5^{b}$ & $16 \pm 4$ \\
\hline
\end{tabular}

$\mathrm{NAD}+\mathrm{NADH}$ content was increased significantly after exposure to NIC $(P<0.001$ vs values of untreated controls). Islets from NOD controls accumulated significant amounts of nitrite, but NIC added to the medium decreased medium nitrite content. NIC 10 was more effective at decreasing the nitrite content (dose-dependent response). ${ }^{a, b} p<0.001$ vs untreated NON and NOD; ${ }^{c} P<0.0001$ vs untreated NON and all NIC-treated animals; d $P<0.001$ vs NIC 20 treated animals. 


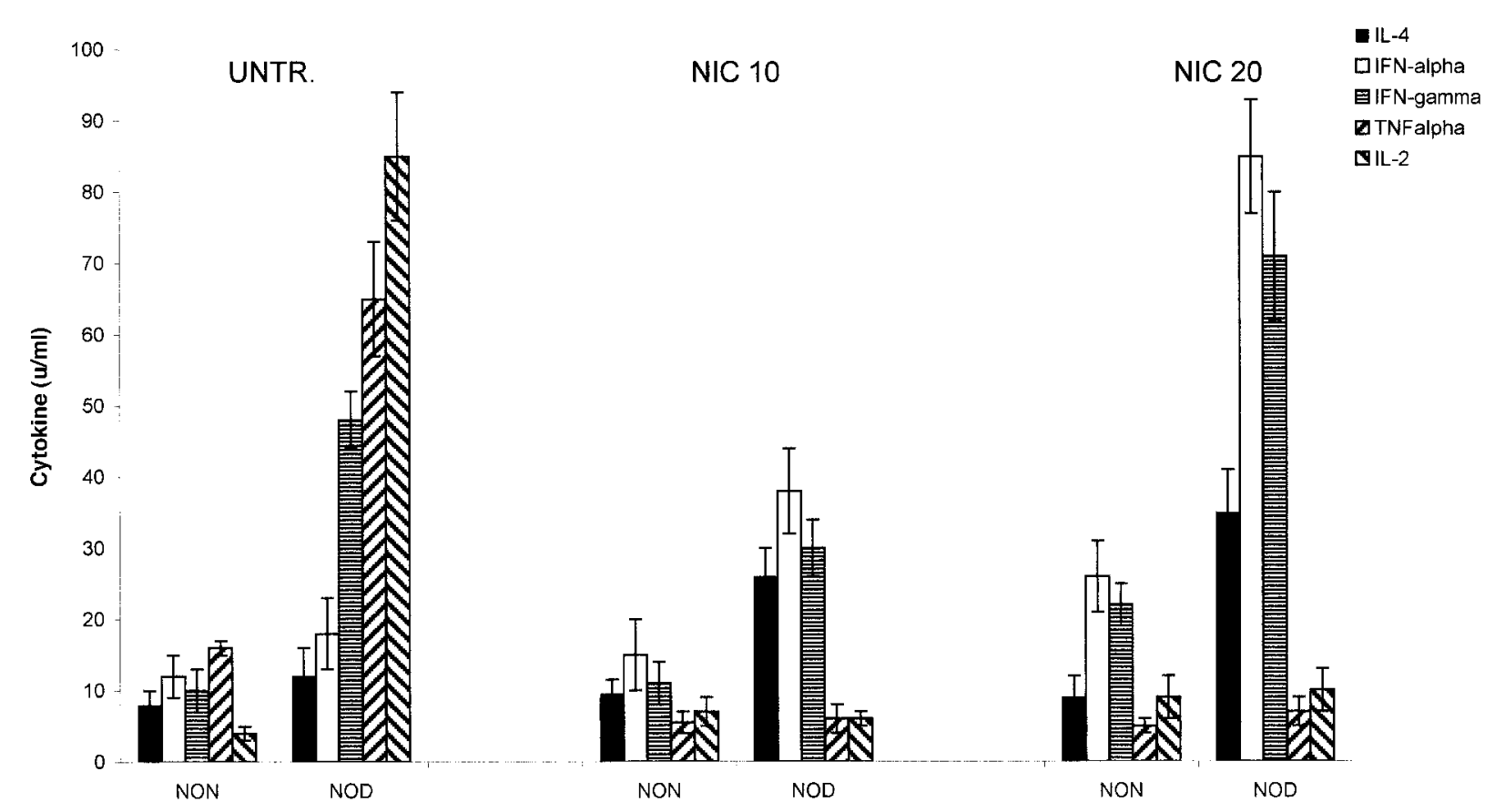

Figure 4 The cytokine profile of NON and NOD islets, untreated (UNTR.) and treated with NIC (10 or $20 \mathrm{mmol} / \mathrm{l})$. Values are expressed as $\mathrm{U} / \mathrm{ml} \pm$ S.D.). NIC-treated islets $(10 \mathrm{mmol} / \mathrm{l})$ from NOD mice showed high levels of IFN- $\alpha(P<0 \cdot 001 \mathrm{vs} \mathrm{NON})$ as well as IL-4 $(P<0.001$ vs NON) production. NIC at $20 \mathrm{mmol} / \mathrm{l}$ further enhanced IFN- $\alpha(P<0 \cdot 001 \mathrm{vs} \mathrm{NOD-NIC} 10 \mathrm{mmol} / \mathrm{l})$, IL-4 (P<0.01 vs NOD-NIC $10 \mathrm{mmol} / \mathrm{l})$ and IFN- $\gamma(P<0.001 \mathrm{vs} \mathrm{NON}$ and NOD-NIC $10 \mathrm{mmol} / \mathrm{l})$ levels. Untreated NOD islets showed high levels of TNF- $\alpha(P<0 \cdot 001$ vs NON and NOD-NIC) and IL-2 ( $P<0.001$ vs NON and all NON-NIC groups) cytokines. Untreated NOD animals showed high levels of IFN- $\gamma(P<0 \cdot 001$ vs NON and NOD-NIC $10 \mathrm{mmol} / \mathrm{l})$. Student's t-test followed by Bonferroni method was used for statistical analysis.

$10 \mathrm{mmol} / \mathrm{l})$. Control untreated islets from diabetic NOD animals showed high levels of TNF- $\alpha(P<0 \cdot 001$ vs NON and NOD-NIC) and IL-2 $(P<0 \cdot 001$ vs NON and NON-NIC) cytokines (Fig. 4). Moreover, islets from diabetic NOD animals showed high levels of IFN- $\gamma$ $(P<0 \cdot 001$ vs NON $)$, though their levels were significantly lower with respect to those observed in NIC-treated NOD $(P<0 \cdot 001)$. The expression of the proinflamatory Th1 cytokines IL- 2 and TNF- $\alpha$ predicts $\beta$ cell destruction in diabetic untreated NOD islets, whereas increased expression of a Th2 cytokine such as IL-4 is protective. Data demonstrate that NIC is able to significantly increase the levels of a protective Th2 cytokine and of IFN- $\alpha$, which in turn is known to be able to induce MHC class I and ICAM-1 but not MHC class II (Chakrabarti et al. 1996). Moreover, NIC is not only able to increase IFN- $\alpha$ levels but also IFN- $\gamma$, which efficiently are also able to induce MHC class I and ICAM-1 (Chakrabarti et al. 1996).

\section{Discussion}

The present study demonstrates the following facts. (1) MHC class I and II and ICAM-1 structures are expressed not only at the level of the connective layer of the ducts, as previously shown in 8-week-old animals (Papaccio et al. 1995), but also are clearly observable at the level of epithelial cells lining the ducts in 10-week-old mice. (2) Adhesive molecules are still expressed mainly at the ductal level in 25-week-old diabetic animals, but they do not express significant amounts of MHC class I and II molecules. (3) $\mathrm{CD}^{+}$and $\mathrm{BM}^{+}$cells are the prevailing infiltrating elements in pre-diabetic ducts. $\mathrm{CD}^{+}$cells, while extremely scarce, are the only infiltrating cells still present in overtly diabetic animals. (4) NIC affects glycaemia and insulitis in animals showing a less severe progression of diabetes. Moreover, it significantly decreases MHC class II, but not class I, expression and significantly enhances ICAM-1 molecules. In 25-week-old animals, these structures are particularly increased on ducts and on small clusters of cells within the exocrine pancreas, where BrdU positive nuclei are also present, although as a small percentage. (5) The co-staining for BrdU and insulin may suggest that insulin-co-staining $\beta$ cells try to proliferate after NIC treatment. (6) NIC is able to significantly counteract the fall in SOD levels observed in diabetic NOD animals and, in particular, $\mathrm{Cu}-\mathrm{Zn}$ SOD values, which are most affected by diabetes progression in the NOD mouse. (7) In vitro studies show that NIC significantly reduces medium nitrite accumulation after 6 days of culture, and is capable of increasing 
$\mathrm{NAD}+\mathrm{NADH}$ content. Moreover, it is able to significantly increase the levels of IL-4, a protective Th2 cytokine, as well as the proinflammatory IFN- $\alpha$ and IFN $-\gamma$ cytokines. In fact, NIC-treated islets from NOD mice show high levels of IL-4 production and, in particular, islets treated using higher amounts of NIC show the highest levels of IL-4, IFN- $\alpha$ and IFN- $\gamma$. Conversely, control untreated islets from diabetic animals show high levels of TNF- $\alpha$ and IL-2, both Th1 destructive cytokines.

The expression of the proinflammatory Th1 cytokines IL- 2 and TNF- $\alpha$ predicts $\beta$ cell destruction in diabetic untreated NOD islets, whereas increased expression of Th2 cytokine IL-4 is protective. Therefore, NIC seems to be able to significantly increase the levels of a protective Th2 cytokine, and also of IFN- $\alpha$, which is known to be able to induce MHC class I and ICAM-1 but not MHC class II molecules (Chakrabarti et al. 1996). On the other hand, although IFN- $\alpha$ is not itself considered to be a Th2 cytokine (Manetti et al. 1995), it exerts several important anti-inflammatory actions, including an anti-diabetogenic role, suggested by the observation that poly I:C, an IFN- $\alpha$ inductor, protects NOD mice from diabetes (Rossini et al. 1995). The said protective effect should be mediated, at least in part, by the ability of IFN- $\alpha$ to counteract IL-1 which, in turn, is involved in the pathogenesis of type 1 diabetes in NOD mice (Nicoletti et al. 1994), up-regulating IL-1 receptor antagonist production.

Moreover, NIC is not only capable of increasing the levels of IFN- $\alpha$ and IL-4, but also of increasing the amount of IFN $-\gamma$, which efficiently induces MHC class I and ICAM-1 molecules (Chakrabarti et al. 1996). Interestingly, islets from diabetic NOD animals in this study show high levels of IFN- $\gamma(P<0 \cdot 001$ vs NON), though these levels were significantly lower with respect to those observed in NIC-treated NOD animals $(P<0 \cdot 001)$.

High levels of IFN- $\gamma$, a proinflammatory Th1 cytokine, found in this study seem to be partly in contrast with the supposed protective role exerted by NIC. Actually, a recent study (Nicoletti et al. 1998) describes a 'paradoxical' anti-diabetogenic effect exerted by IFN- $\gamma$ in diabetesprone bio breeding rats. This cytokine, as indicated above, is able to induce both MHC class I and ICAM-1 expression, as other Th2 protective cytokines do, although it is known to be a proinflammatory destructive Th1 cytokine. Therefore, a revision of its action and role in type 1 diabetes, as the recent findings stress (Nicoletti et al. 1998), will contribute to understanding not only its specific role but probably even the reasons for the alternating success or failure of NIC treatment in protecting against type 1 diabetes development.

In the present study, NIC significantly enhanced ICAM-1 expression both in islets and in extra-islet areas of NOD pancreas during the pre-diabetic stage (10-weekold animals), where ICAM-1 structures were also observed at the level of the epithelial layer of ducts. This increased expression was paralleled by a decrease in MHC class II but not in class I expression, confirming previous data from Yamada et al. (1990, 1993) suggesting that class II antigen expression is inhibited by NIC and 3 -aminobenzamide. These authors speculate that the agents are hydroxyl radical scavengers as well as inhibitors of poly(ADP-ribose) synthetase which can penetrate cells; therefore hydroxyl radicals may play a role in class II antigen expression on islet cells, although the mechanism is unknown (Yamada et al. 1993). Moreover, the expression of those structures may be regulated by distinct mechanisms in islet cells, since class I antigen augmentation is not affected by free radical scavengers (Yamada et al. 1993). Normal mouse islet cells, as well as ductal cells, have undetectable or extremely low levels of MHC class II molecules. Islet $\beta$ cells of NOD mice have been shown to express significant levels of MHC class II antigens (Hanafusa et al. 1987), although this observation is controversial (Signore et al. 1989). Class II expression might result in the presentation of self-antigens to helper $\mathrm{T}$ lymphocytes and initiation of autoimmune responses to islet $\beta$ cells (Bottazzo et al. 1983). As suggested by Harrison et al. (1989), inappropriate expression of MHC molecules may interfere with key cellular functions. Therefore, the decrease in class II molecule expression may result in the protection of islet cells (Yamada et al. 1990). More recently, it has been shown that accumulation of $\beta$-cytotoxic T-cell clones in islets is an MHC class I-restricted phenomenon (Utsugi et al. 1996).

The over-expression of adhesion molecules (ICAM-1) at various levels (islets, ductal cells, endothelia and cells along septa) exerted by NIC treatment may also be involved in the conflicting results obtained with NIC, mainly in vivo, reported by different researchers.

The ICAM-1 enhancement exerted by NIC treatment can be partly explained either as a persistence of the immune mechanisms of recognition, adhesion and cytolysis, or as a possible endocrine regeneration and/or differentiation process, as the noted expression and the BrdU positivity imply.

A further point stressed by this work concerns the expression of both Ia-b and ICAM-1 within the epithelial layer of the ducts, which has not previously been observed in younger animals (8-week-old), and, in particular, the persistence of ICAM-1 on these elements in overtly diabetic mice. These findings could be explained by the kinetics of the progression of the disease in which class II and adhesion molecules are first expressed by infiltrating cells and elements of the connective tissue surrounding the ducts (including less differentiated elements such as mesenchymal cells), and, then, by the epithelial cells which become involved in the infiltration process during which mononuclear cells reach the epithelial surface. Nearing the end of infiltration in untreated NOD animals, the decrease in MHC class I and II expression is mirrored by ICAM-1. NIC has the ability to maintain an increased 
expression of ICAM-1, preceded by a significant decrease in MHC class II expression.

Until now, the expression of ICAM-1 was found to be limited to the cells (endothelia or islet $\beta$ cells) facing infiltrating lymphocytes, as a consequence of local accumulation of cytokines generated by infiltrated cells. For endothelia, this has been interpreted to be a contribution to the extravasation of mononuclear cells into the inflammatory sites, thus favouring the recruitment of these cells (Dustin et al. 1988, Springer 1990), and, for islet $\beta$ cells, an induction by cytokines which facilitates the destruction of these cells by $\mathrm{CD}^{+}$CTLs by means of an ICAM-1/ LFA-1 interaction which takes place between islet $\beta$ cells and adjacent T-lymphocytes (Yang et al. 1996). ICAM-1 positivity in pancreatic ducts is not related to facing infiltrating lymphocytes, but could be induced by locally released cytokines which have been shown to induce ICAM-1 expression, as the present study demonstrates. The apparent absence of ICAM-1 on normal adult endocrine islet and epithelial cells lining ducts, its induction by autoimmune mechanisms which take place in type 1 diabetes, its persistence in pancreatic ducts of overtly diabetic animals, and its enhancement exerted by NIC treatment suggest that the role of ICAM-1 is not only to facilitate interaction between cells of the immune and endocrine systems but also to aid interactions between these cells after the loss of insulin-containing $\beta$ cells (located there) for a possible attempt at neo-histogenesis. Such a role could also be suggested by the low level of class II MHC protein in diabetic animals, which is decreased further by NIC treatment. Alternatively, NIC has been reported to induce differentiation and maturation of human pancreatic cells (Otontoski et al. 1993), a finding which may further support our results.

Moreover, despite its anti-oxidant effects, NIC does not completely protect NOD mice from diabetes development in this study. The beneficial effects of NIC are inhibition of NO synthesis, prevention of cellular NAD depletion and the scavenging of oxygen free radicals by increasing SOD, the first cellular defence against free radicals. Because NIC may prevent both cytokine-induced NO formation (Eizirik et al. 1994) and production of oxygen free radicals (Wilson et al. 1984), it would appear that combining these two effects might lead to an understanding of the cellular mechanisms by which it could exert beneficial effects against type 1 diabetes development. Although controlled in vitro conditions showed some beneficial effects, the present study confirms that in vivo NIC does not completely prevent islet $\beta$ cell destruction. In fact, several previous studies have attempted to clarify the action of NIC and its ability to counteract or prevent diabetes, but the results have often been conflicting. This study shows that, although this drug has several positive actions, it does not act synergistically in completely preventing or blocking the development of the disease. The results shown by some authors seem to be in favour
(Yamada et al. 1982), while others are against (Hermitte et al. 1989), a supposed anti-diabetic role for NIC. Recent trials in humans did not provide new insights, just suggesting that the drug can preserve and improve stimulated islet $\beta$ cell function only in patients diagnosed after puberty (Pozzilli et al. 1995).

\section{Acknowledgements}

This work was supported by MURST (60\%) and Campania Region funds. The authors are grateful to Mr Georgios Daphnys (Zoological Station 'A Dohrn', Naples, Italy) for technical help and to Dr J J Gartland, Medical Editor, Thomas Jefferson University, Philadelphia, PA, USA, for reading the manuscript.

\section{References}

Asamoto H, Akazawa Y, Tashiro S, Oishi M, Azuma T, Koide S, Sudo K, Yokota H \& Tochino Y 1984 Infiltration of lymphocytes in various organs of the NOD mouse. Journal of the Japanese Diabetic Society 27 775-781.

Bonner-Weir S, Baxter LA, Schuppin GT \& Smith FE 1993 A second pathway for regeneration of adult exocrine and endocrine pancreas. A possible recapitulation of embryonic development. Diabetes $\mathbf{4 2}$ 1715-1720.

Bottazzo GF, Pujol-Borrell R, Hanafusa T \& Feldmann M 1983 Role of aberrant HLA-DR expression and antigen presentation in induction of endocrine autoimmunity. Lancet 2 1115-1118.

Bretzel RG, Flesch BK, Willig J, Woehrle M \& Federlin K 1990 Effects of gangliosides (Cronassial) treatment on MHC Ia antigen expression and allograft survival of pancreatic islets in diabetic rats. Diabetologia 33 112-114.

Brunstedt J, Nielsen JH, Lernmark ^̊ \& Hagedorn Study Group 1984 Isolation of islets from mice and rats. In Methods in Diabetes Research, vol 1, pp 254-288. Eds J Larner \& SL Pohl. New York: Wiley Co.

Chakrabarti D, Huang X, Beck J, Henrich J, McFarland N, James RFL \& Stewart TA 1996 Control of islet intercellular adhesion molecule-1 expression by interferon- $\alpha$ and hypoxia. Diabetes 45 1336-1343.

Dustin ML, Rothlein R, Bhan AK, Dinarello CA \& Springer TA 1986 Induction by IL-1: tissue distribution, biochemistry, function of a natural adherence molecule (ICAM-1). Journal of Immunology 137 245-254.

Dustin ML, Singer KH, Tuck DT \& Springer TA 1988 Adhesion of $\mathrm{T}$ lymphoblasts to epidermal keratinocytes is regulated by interferon $\gamma$ and is mediated by inter-cellular-adhesion-molecule 1 (ICAM-1). Journal of Experimental Medicine 167 1323-1340.

Eizirik DL, Sandler S, Welsh N, Bendtzen K \& Hellerström C 1994 Nicotinamide decreases nitric oxide production and partially protects human pancreatic islets against the suppressive effects of combination of cytokines. Autoimmunity 19 193-198.

Green LS, Wagner DA, Glogowski J, Skipper PL, Wishnok JS \& Tannenbaum SR 1982 Analysis of nitrate, nitrite and $\left[{ }^{15} \mathrm{~N}\right]$ nitrate in biological fluids. Analytical Biochemistry 126 131-138.

Hanafusa T, Fujino-Kurihara H, Miyazaki A, Yamada K, Nakajima H, Miyagawa J, Kono N \& Trui S 1987 Expression of class II major histocompatibility complex antigens on pancreatic B cells in the NOD mouse. Diabetologia 30 104-108.

Hänninen A, Jalkanen S, Salmi M, Toikkanen S, Nikilakros G \& Simell O 1992 Macrophages, T cell receptor usage and endothelial cell activation in the pancreas at the onset of insulin-dependent diabetes mellitus. Journal of Clinical Investigation 90 1901-1910. 
Harrison LC, Campbell IL, Allison J \& Miller JFAP 1989 MHC molecules and $\beta$-cell destruction: immune and non-immune mechanisms. Diabetes 38 815-818.

Hermitte L, Vialettes B, Atlef N, Payan MJ, Doll N, Scheimann A \& Vague $\mathrm{Ph} 1989$ High dose nicotinamide fails to prevent diabetes in B rats. Autoimmunity 5 79-86.

Isobe M, Yagita H, Okumura K \& Ihara A 1992 Specific acceptance of cardiac allograft after treatment with antibodies to ICAM-1 and LFA-1. Science 255 1125-1127.

Linn T, Strate C, Federlin K \& Papaccio G 1994 Inter-cellularadhesion-molecule-1 (ICAM-1) expression in the islets of nonobese diabetic (NOD) and low-dose streptozocin-treated mouse pancreas. Histochemistry 97 371-374.

McCord JM \& Fridovich I 1969 Superoxide dismutase: an enzymatic function for erythrocuprein. Journal of Biological Chemistry 244 256-275.

Makgoba MW, Sanders ME, Luce GEG, Gugel EA, Dustin ML, Springer TA \& Shaw S 1988 Functional evidence that intercellular adhesion molecule-1 (ICAM-1) is a ligand for LFA-1-dependent adhesion in T-cell-mediated cytotoxicity. European Journal of Immunology 18 637-640.

Manetti R, Annunziato F, Tomasevic L, Gianno V, Parronchi P, Romagnani S \& Maggi E 1995 Polyinosinic acid:polycytidylic acid promotes $\mathrm{T}$ helper type 1 -specific immune responses by stimulating macrophage production of interferon alpha and IL-12. European Journal of Immunology 25 2656-2660.

Miyagawa J-I, Hanafusa T, Miyazaki A, Yamada K, Fujino-Kurihara H, Nakasima H, Kono N, Nokada K, Tochino Y \& Tarui S 1986 Ultrastructural and immunocytochemical aspects of lymphocytic submandibulitis in the non-obese diabetic (NOD) mouse. Virchows Archiv $\mathbf{5 1}$ 215-225.

Nicoletti F, Di Marco R, Barcellini W, Magro G, Schorlemmer HU, Kurrle R, Lunetta M, Grasso S, Zaccone P \& Meroni PL 1994 Protection from experimental autoimmune diabetes in the nonobese diabetic mouse with soluble interleukin-1 receptor. European Journal of Immunology 24 1843-1847.

Nicoletti F, Zaccone P, Di Marco R, Magro G, Grasso S, Stivala F, Calori G, Mughini L, Meroni PL \& Garotta G 1998 Paradoxical antidiabetogenic effect of $\gamma$-interferon in DP-BB rats. Diabetes 47 32-38.

Openshaw P, Murphy EE, Hosken NA, Maino V, Davis K, Murphy K \& O'Garra A 1995 Heterogeneity of intracellular cytokine synthesis at the single-cell level in polarized $\mathrm{T}$ helper 1 and $\mathrm{T}$ helper 2 populations. Journal of Experimental Medicine $\mathbf{1 8 2}$ 1357-1367.

Otontoski T, Beattie GM, Mally MI, Ricordi C \& Hayek A 1993 Nicotinamide is a potent inducer of endocrine differentiation in cultured human fetal pancreatic cells. Journal of Clinical Investigation 92 1459-1466.

Papaccio G, Linn T, Federlin K, Volkmann A, Esposito V \& Mezzogiorno V 1991 Further morphological and biochemical observations on early low dose streptozocin diabetes in mice. Pancreas 6 659-667.

Papaccio G, Chieffi Baccari G, Mezzogiorno V \& Esposito V 1993a Extraislet infiltration in NOD mouse pancreas: observations after immunomodulation. Pancreas 8 459-464.

Papaccio G, Linn T \& Chieffi Baccari G 1993 b Morphological observations on pancreatic islet blood vessels in low-dose streptozocin-treated mice. Journal of Anatomy 182 45-53.

Papaccio G, Chieffi Baccari G, Strate C \& Linn T 1995 Pancreatic duct inflammatory infiltration in the non-obese diabetic (NOD) mouse. Journal of Anatomy 185 465-470.

Papaccio G, Sellitti S, Salvatore G \& Chieffi Baccari G 1996 The Harderian gland in autoimmune diabetes of the non-obese diabetic mouse. Microscopy Research and Technique 33 156-165.

Pozzilli P, Visalli N, Signore MG, Buzzetti R, Cavallo MG, Boccuni ML, Fava D, Gragnoli C, Andreani D, Lucentini L, Matteoli MC,
Crinò A, Cicconetti CA, Teodonio C, Paci F, Amoretti R, Pisano L, Pennafina MG, Santopadre G, Marozzi G, Multari G, Suppa MA, Campea L, De Mattia GC, Cassone Faldetta M, Marietti G, Perrone F, Greco AV \& Ghirlanda G 1995 Double blind trial of nicotinamide in recent-onset IDDM (the IMIDIAB III study). Diabetologia 38 848-852.

Rossini AA, Handler ES, Mordes JP \& Greiner DL 1995 Human autoimmune diabetes mellitus: lessons from $\mathrm{BB}$ rats and NOD mice - Caveat emptor. Clinical Immunology and Immunopathology $\mathbf{7 4}$ 2-9.

Sandler S \& Andersson A 1988 Nicotinamide treatment stimulates cell replication in transplanted pancreatic islets. Transplantation $\mathbf{4 6}$ 30-31.

Sandler S, Andersson A, Korsgren O, Tollemar J, Petersson B, Groth C-G \& Hellerström C 1989 Tissue culture of human fetal pancreas. Effects of nicotinamide on insulin production and formation of islet like cell clusters. Diabetologia 38 (Suppl 1) 168-171.

Signore A, Pozzilli P, Gale EMA, Andreani D \& Beverley PCL 1989 The natural history of lymphocyte subsets infiltrating the pancreas of NOD mice. Diabetologia 32 282-289.

Springer TA 1990 Adhesion receptors of the immune system. Nature 346 425-434.

Strandell E, Eizirik DL, Korsgren O \& Sandler S 1988 Functional characteristics of cultured mouse pancreatic islets following exposure to different streptozotocin concentrations. Molecular and Cellular Endocrinology 59 83-91.

Utsugi T, Yoon J-W, Park B-J, Iamamura M, Averill N, Kawazu S \& Santamaria P 1996 Major histocompatibility complex class I-restricted infiltration and destruction of pancreatic islets by NOD mouse-derived $\beta$-cell cytotoxic $\mathrm{CD}^{+} \mathrm{T}$-cell clones in vivo. Diabetes 45 1121-1131.

Wallenstein S, Zucher CL \& Fleiss J 1980 Some statistical methods useful in circulation research. Circulation Research 47 1-9.

Wang RN, Klöppel G \& Bouwens L 1995 Duct to islet cell differentiation and islet growth in the pancreas of duct-ligated adult rats. Diabetologia 38 1405-1411.

Wilson GL, Patton NJ, McCord JM, Mullins DW \& Mossman BT 1984 Mechanisms of streptozocin- and alloxan-induced damage in rat B cells. Diabetologia 27 587-591.

Yagi N, Yokono K, Nagata M, Tsukamoto K, Hasegawa Y, Yoneda R, Okamoto N, Moriyama H, Miki M, Tominaga Y, Miyazaki J, Yagita H, Okumura K, Mizoguchi A, Miki A, Ide C, Maeda S \& Kasuga M 1995 Expression of intercellular adhesion molecule 1 on pancreatic $\beta$ cells accelerates $\beta$ cell destruction by cytotoxic T-cells in murine autoimmune diabetes. Diabetes 44 744-752.

Yamada K, Nonaka K, Hanafusa T, Miyazaki A, Toyoshima H \& Tarui S 1982 Preventive and therapeutic effects of large dose nicotinamide injections on diabetes associated with insulitis. An observation in non-obese diabetic (NOD) mice. Diabetes $\mathbf{3 1}$ 749-753.

Yamada K, Miyajima E \& Nonaka K 1990 Inhibition of cytokineinduced MHC class II but not class I molecule expression on mouse islet cells by niacinamide and 3-aminobenzamide. Diabetes 39 $1125-1130$

Yamada K, Inada C, Otabe S, Takane N, Hayashi H \& Nonaka K 1993 Effects of free radical scavengers on cytokine actions on islet cells. Acta Endocrinologica 128 379-384.

Yang X-D, Michie SA, Mebius RE, Tisch R, Weissman I \& McDevitt HO 1996 The role of cell adhesion molecules in the development of IDDM. Implications for pathogenesis and therapy. Diabetes 45 705-710.

Received 29 June 1998

Accepted 20 October 1998 